\title{
Cultivar and Tree Density As Key Factors in the Long-Term Performance of Super High-Density Olive Orchards
}

\section{OPEN ACCESS}

Edited by:

Jose I. Hormaza

Spanish National Research Council,

Spain

Reviewed by:

Theodore M. DeJong,

University of California, Davis, USA

George A. Manganaris,

Cyprus University of Technology,

Cyprus

Javier Rodrigo,

Centro de Investigación y Tecnología

Agroalimentaria de Aragón, Spain

*Correspondence:

Concepción M. Díez

cmdiez@uco.es

Juan Moral

jmoral@ucdavis.edu

${ }^{\dagger}$ These authors have contributed equally to this work

Specialty section:

This article was submitted to Crop Science and Horticulture,

a section of the journal

Frontiers in Plant Science

Received: 11 May 2016 Accepted: 02 August 2016 Published: 23 August 2016

Citation:

Díez CM, Moral J, Cabello D, Morello $P$, Rallo $L$ and Barranco $D$ (2016) Cultivar and Tree Density As

Key Factors in the Long-Term Performance of Super High-Density Olive Orchards.

Front. Plant Sci. 7:1226. doi: 10.3389/fpls.2016.01226

\author{
Concepción M. Díez ${ }^{1 * \dagger}$, Juan Moral ${ }^{1,2 * \dagger}$, Diego Cabello ${ }^{1}$, Pablo Morello ${ }^{1}$, Luis Rallo ${ }^{1}$ and \\ Diego Barranco ${ }^{1}$
}

${ }^{1}$ Departamento de Agronomía, Campus de Excelencia Internacional Agroalimentario (ceiA3), Universidad de Córdoba, Córdoba, Spain, ${ }^{2}$ Department of Plant Pathology, Kearney Agricultural Research and Extension Center, University of California, Davis, Davis, CA, USA

Super high-density (SHD) olive orchards are rapidly expanding since the first plantation was set up in Spain in the 1990s. Because there are no long-term studies characterizing these systems, it is unknown if densities above a certain threshold could trigger competition among fully-grown trees, compromising their development. Over 14 years we have evaluated the performance of the major olive cultivars currently planted in SHD systems ("Arbequina," Arbequina IRTA-i.18, "Arbosana," "Fs-17," and "Koroneiki") and nine SHD designs ranging from 780 to 2254 trees ha $^{-1}$ for the cultivar "Arbequina." Remarkably, the accumulated fruit and oil production of the five cultivars increased linearly over time. Our data indicated the favorable long-term performance of the evaluated cultivars with an average annual oil production of $2.3 \mathrm{t} \mathrm{ha}^{-1}$. Only "Fs-17" did not perform well to the SHD system in our conditions and it yielded about half $\left(1.2 \mathrm{t} \mathrm{ha}{ }^{-1}\right)$ of the other cultivars. In the density trial for "Arbequina," both fruit and oil accumulated production increased over time as a function of tree density. Thus, the accumulated oil yield ranged from $16.1 \mathrm{t} \mathrm{ha}^{-1}$ for the lowest density $\left(780\right.$ trees ha $\left.{ }^{-1}\right)$ to $29.9 \mathrm{t} \mathrm{ha}^{-1}$ for the highest (2254 trees $\mathrm{ha}^{-1}$ ). In addition, we note that the accumulated production per surface unit showed a better correlation with the hedgerow length than the tree density. Thus, the current planting designs of SHD olive orchards can be further improved taking this parameter into account. Despite observations that some irregular patterns of crop distribution have arisen, our olive hedgerows are still fully productive after 14 years of planting. This result contradicts previous experiences that showed declines in production 7 or 8 years after planting due to high vigor, shading, and limited ventilation.

Keywords: Olea europaea L., orchard design, oil yield, biennial bearing, hedgerows

\section{INTRODUCTION}

Traditional Mediterranean olive orchards are designed in the form of extensive plantations with densities of $70-80$ trees $\mathrm{ha}^{-1}$. However, hedgerow orchards are gaining popularity worldwide; these are also known as super high-density (SHD) systems, narrow hedgerows with an average of 1500-2000 trees $\mathrm{ha}^{-1}$. Compared to traditional systems, these SHD orchards have several advantages, including rapid mechanized harvesting and pruning, high crop levels, and early 
bearing. These features make SHD systems profitable, and thus they are commonly chosen for new plantations, especially in nontraditional olive-growing countries, such as Argentina, Australia, and the USA (Rallo et al., 2013; Connor et al., 2014). Currently, there are more than 100,000 ha of SHD olive orchards worldwide, and this number is growing (Rius and Lacarte, 2015).

A major drawback associated with SHD systems is that they require high initial investments; in addition, limited information has led to uncertainties concerning their optimum design, suitable cultivars, management strategies, and longevity (Freixa et al., 2011; Rallo et al., 2013; Connor et al., 2014). This lack of knowledge stems from the relatively recent development of SHD systems for olives and the sparseness of scientific and technical research. SHD systems were first applied to other fruit crops including apples, peaches, and cherries (Ryugo and Mikuckis, 1969; Heinicke, 1975; DeJong and Doyle, 1985). In these crops, the spread of SHD systems was enhanced by the development of new training systems, low-vigor cultivars, and dwarfing rootstocks (Webster, 1993; Day et al., 2005; Robinson, 2005; Robinson et al., 2013; Musacchi et al., 2015).

The first SHD olive orchards were established during the 1990 s in Spain and were primarily promoted by private companies (Rius and Lacarte, 2015). Since then, commercial olive production has advanced more rapidly than scientific research regarding the response of olives to SHD. Lately, however, technical research has made significant strides in characterizing and evaluating the factors that affect the performance of SHD olive orchards.

The success of olive SHD systems in Mediterranean areas largely depends on careful management of water and nutrients to control the vigor of the trees, as well as the optimum combination of a suitable cultivar and appropriate orchard design (Rallo et al., 2013; Connor et al., 2014). The two latter factors are especially critical in rain fed SHD olive orchards, which are currently being planted in areas with low to medium rainfall such as the Guadalquivir Valley in southern Spain. The use of low vigor cultivars is also crucial in SHD systems, because shadowing problems can arise more quickly for vigorous cultivars, compromising the long-term health of the orchard (Rallo et al., 2013).

Only a few traditional olive cultivars meet the low vigor required by SHD systems. In addition, no rootstocks, able to modify the scion growth habit, have been developed for olive because, in contrast to other fruit crops, olive cultivars primarily grow from their own roots (Barranco, 2010). The traditional cv. "Arbequina" is by far the dominant cultivar used in SHD orchards given its low vigor, high and stable productivity, and fruity oil (Barranco et al., 2000; Rius and Lacarte, 2015). SHD systems also include two other traditional cultivars that have low or moderate vigor, "Arbosana" and "Koroneiki" (Barranco et al., 2000; Tous et al., 2011; Rallo et al., 2013). The cultivars "Arbequina” and "Arbosana" share a compact architectural pattern that increases yield efficiency in SHD conditions compared to other cultivars (Rosati et al., 2013). "Koroneiki" is also a highly productive cultivar that yields high-quality oils, but it is more vigorous than "Arbequina" and "Arbosana" (Barranco et al., 2000). However, the extent to which the different vigor and growth habits of the
"Arbequina," “Arbosana," and "Koroneiki” cultivars will affect the long-term performance of SHD orchards is unknown.

The distance between trees and rows primarily defines the orchard design, which is also constrained by the availability of irrigation water and the orientation of the rows (Pastor et al., 2007; Rallo et al., 2013; Rosecrance et al., 2015; Trentacoste et al., 2015a,b). An optimum orchard design should favor maximum yields without compromising the management of the orchard, for example, by still allowing access by harvester machines and other vehicles. High yields are significantly influenced by the illumination of the hedgerows, which is primarily determined by the ratio (D/A) of canopy depth to free alley width (i.e., the row spacing minus the hedgerow width). As with other fruit crops, in $\mathrm{N}-\mathrm{S}$ oriented rectangular olive orchards, oil yield is maximized when the canopy depth equals the free alley width $(\mathrm{D} / \mathrm{A}=1$; Smart et al., 1990; Robinson, 2011; Connor and Gómez-delCampo, 2013). During the first years after planting, the oil yield increases linearly with tree density (De la Rosa et al., 2007; León et al., 2007; Larbi et al., 2011, 2012; Farinelli and Tombesi, 2015). However, it is still unknown if densities above a certain threshold can trigger competition among fully-grown trees, compromising their development and production and ultimately the lifespan of the olive orchard. Long-term comparative trials are necessary to resolve this debate (Rallo et al., 2013).

To date, all the studies have characterized SHD olive systems during the first 4-7 years after planting (Hermoso et al., 2004; Camposeo and Godini, 2010; Larbi et al., 2011, 2012; Tous et al., 2011; Proietti et al., 2014; Farinelli and Tombesi, 2015; Trentacoste et al., 2015a); and no long-term evaluations that exceed this period have been published. This situation is especially striking given the global spread of SHD olive orchards (Rius and Lacarte, 2015). Overall, this study aims to address this gap in knowledge by evaluating SHD orchard designs and cultivars in two comparative field trials over a 14 year period. It also tries to address the following specific questions. First, which are the best-suited cultivars for SHD olive orchards? Second, what is the average oil production for this kind of orchard design over a long-term period? Does the production decline over time? Finally, what is the effect of increasing tree density on production? Does the tree density affect the characteristics of the cultivars?

Preliminary results of these two trials were published 7 years after planting, providing the first description of the early performance of SHD olive orchards (De la Rosa et al., 2007; León et al., 2007). Now, after 14 years, the two trials are still fully productive. Despite some irregular patterns of crop distribution were detected, the trials did not present the problems previously reported for SHD orchards at 7 years after planting (Pastor et al., 2007). The selection of the cultivar, the orchard design as well as, the control of the tree vigor, emerge as critical factors to guarantee the production and longevity of SHD olive orchards.

\section{MATERIALS AND METHODS}

\section{Trial Location and Management}

Two trials were conducted over 14 years to assess the response of five olive cultivars, "Arbequina," Arbequina IRTA-i-18, 
"Arbosana," "Fs-17," and "Koroneiki," to SHD conditions and determine the optimum SHD design for the cultivar "Arbequina." Both trials were located in Pedro Abad, Cordoba, in southern Spain $\left(37^{\circ} 57^{\prime} 32^{\prime \prime} \mathrm{N}, 4^{\circ} 27^{\prime} 44^{\prime \prime} \mathrm{W}\right.$ and $162 \mathrm{~m}$ a.s.l.) in a plot owned by the company Todolivo S.L. The climate of the area is Mediterranean; the average annual precipitation from 2001 to 2013 was $566 \mathrm{~mm}$, and there was marked summer drought with less than $30 \mathrm{~mm}$ of precipitation from June to September. The average potential evapotranspiration (ETP) from 2001 to 2013 was $938 \mathrm{~mm}$, and the average annual, maximum and minimum temperatures were $17.5,24.9$, and $10.3^{\circ} \mathrm{C}$, respectively (Tragsa, 2015). The area of study was an alluvial plain formed by deposition of Guadalquivir river and the soil was classified as a Typic Xerofluvent (Soil Survey Staff, 2015). The soil was $\sim 1.5 \mathrm{~m}$ deep and with a sandy-loam Ap upper horizon (0$35 \mathrm{~cm}), \mathrm{pH}=8.1$, and $1.2 \%$ of organic matter content. The available phosphorous $(\mathrm{P})$ and potassium $(\mathrm{K})$ contents in the soil were 19.2 and $418 \mathrm{mg} \mathrm{kg}^{-1}$, respectively. Field capacity and permanent wilting point were 0.23 and $0.07 \mathrm{~m}^{3} \mathrm{~m}^{-3}$, respectively (Testi et al., 2004). These latter values were not determined for the experimental plots but for a geographically nearby olive orchard with similar soil characteristics.

The trials were set up in March of 2000, when $50 \mathrm{~cm}$-tall, selfrooted olive trees were planted. The rows were oriented north to south, and the trees were trained to a central leader to promote hedgerow formation, after which they were pruned annually with the exception of 2011 and 2013. The olive trees were also pruned to remove shoots up to $50 \mathrm{~cm}$ off the ground and lateral branches extending into alleys. Automatic lateral and top pruning was used to fit the trees to the harvester machine. The sites were irrigated from May to September applying $100 \mathrm{~m}^{3}$ per ha per week $\left(2000 \mathrm{~m}^{3}\right.$ of water per year) using drip irrigation; during some years the same irrigation practice was extended until the end of October. Foliar fertilization was applied four times per year during the months of November (after harvesting), March, May and September, with $2 \%$ potassium nitrate. No fertilizers were intentionally applied to the soil but the nitrate contamination of the irrigation water reached values as high as $87 \mathrm{mg} / \mathrm{l}$, with a median in the area close to $79 \mathrm{mg} / \mathrm{l}$ (López-Gutierrez et al., 2012). Therefore, irrigation approximately supplied $174 \mathrm{~kg}$ of $\mathrm{N} \mathrm{ha}{ }^{-1}$ year $^{-1}$. Pest control and soil management practices were applied according to the conventional practices recommended for SHD olive orchards (Rius and Lacarte, 2015). Three extreme climatic episodes affected the trials during the 14 years of evaluation. First, unusually heavy and prolonged rainy periods caused waterlogging during the winters of 2003-2004 and 2010-2011, when 345 and $522 \mathrm{~mm}$ of rain fell from October to December, respectively. Second, severe frosts damaged the trees during the winters of 2004-2005 and 2011-2012, with temperatures below $-9^{\circ}$ and $-6^{\circ} \mathrm{C}$, respectively. Finally, high temperatures (above $36^{\circ} \mathrm{C}$ for 10 days) in May of 2012 caused ovary abortion and yield loss.

\section{Experimental Design}

The first trial was aimed to evaluate the performance of the cvs. "Arbequina," Arbequina IRTA-i·18, “Arbosana," "Fs-17," and "Koroneiki" in SHD systems. "Arbequina" and "Arbosana" are traditional cultivars from Catalonia, Spain, and "Koroneiki" is a major traditional cultivar from Greece (Barranco et al., 2000). Arbequina IRTA-i.18 is a clone of "Arbequina" selected in Catalonia (Tous et al., 1998), and "Fs-17" is derived from a cross of "Frantoio" in open pollination (Fontanazza et al., 1998). The olive trees were planted with a distance of $3.75 \mathrm{~m}$ between rows and $1.35 \mathrm{~m}$ between the trees (1975 trees $\mathrm{ha}^{-1}$ ). The experimental design was a randomized complete block with four replicates. Every block was composed of four rows with 40 trees of each cultivar as the experimental unit.

The second trial focused on testing the performance of "Arbequina" in nine designs with different tree densities, including 780, 909, 952, 1143, 1203, 1481, 1569, 2000, and 2254 olive trees per ha. These densities were, respectively, the result of the following combinations of distances between rows and trees within rows $(\mathrm{m}): 5.70 \times 2.25,5.50 \times 2.00,5.25 \times 2.00,5.00 \times 1.75$, $4.75 \times 1.75,4.50 \times 1.50,4.25 \times 1.50,4.00 \times 1.25$, and $3.55 \times 1.25$. The experimental design of the trial was a randomized complete block with four replicates, where each experimental unit consisted of a 40 m-long row with 18-32 trees (depending on the density).

\section{Experimental Variables}

Both trials were monitored from 2002 to 2013 (henceforth, from the $3 \mathrm{rd}$ to the 14 th years after planting). The following data were collected.

\section{Fruit Yield}

The fruit was collected on the same day for all the treatments, when the fruits were at a ripening index of 3-4, from violet to black according to Barranco et al. (2005). A harvesting machine was used to collect the fruit, after which the fruit was weighed (in $\mathrm{kg}$ ) for each experimental unit. These measurements allowed us to calculate the annual ( $\mathrm{kg}$ fruit $\mathrm{ha}^{-1}$ year $^{-1}$ ) and accumulated fruit yields ( $\mathrm{kg}$ fruit ha ${ }^{-1}$ ) for every treatment.

\section{Fruit Characteristics and Oil Content}

The fruit characteristics were evaluated by sampling each row, cultivar, and density in triplicate. The average fruit weight was measured in over 100 fresh fruits. The samples were then dried in a forced-air oven at $105^{\circ} \mathrm{C}$ for $42 \mathrm{~h}$. and weighted again to determine the moisture content. The oil percentage was measured in these samples using a NMR analyser Minispec NMS100 (Bruker Optik GmbH, Ettlingen, Germany) according to the method described by del Rio and Romero (1999).

\section{Oil Yield}

Based on the fruit yield and the oil content, we calculated the annual (kg oil ha-1 year $^{-1}$ ) and the accumulated oil yield (kg oil $\left.\mathrm{ha}^{-1}\right)$.

\section{Alternate Bearing}

To study the influence of the cultivar and the tree density on the alternate bearing behavior of the cultivars, we estimated their alternate bearing index (ABI) from the 3rd to the 14th year after planting. The ABI index was calculated using the following formula (Pearce and Doberšek-Urbanc, 1967): 


$$
A B I=\frac{1}{n-1} \sum_{n=1}^{n}\left|\frac{\mathrm{a}_{\mathrm{n}+1}-\mathrm{a}_{\mathrm{n}}}{\mathrm{a}_{\mathrm{n}+1}+\mathrm{a}_{\mathrm{n}}}\right|
$$

Where $n$ is the year and $a_{n}$ is the yield at harvest.

To further characterize the alternate bearing behavior of the different treatments, we also calculated the bienniality index (B; Monselise and Goldschmidt, 1982), which indicates the percentage of occasions in which increasing or decreasing trends in yield were reversed between successive pairs of years. Both the $\mathrm{ABI}$ and $\mathrm{B}$ indexes range from 0 to 1 , where 0 indicates no alternate and 1, maximum alternate bearing.

\section{Vigor}

The vigor of the adult trees was characterized by measuring their canopy depth and width (Connor and Gómez-del-Campo, 2013) during the 12th and 13rd winters after planting. The hedgerow volume and external surface area were calculated by considering the hedgerow as a rectangular parallelepiped; we used the following equations:

$$
\begin{aligned}
& \text { Canopy volume }\left(m^{3} h a^{-1}\right)=(h-t) \times w \times r \times n \\
& \text { External surface area }\left(m^{2} h a^{-1}\right)=[2((h-t) \times r) \\
&+(w \times r)] \times n
\end{aligned}
$$

Where $h$ is the canopy height, $t$ is the height above ground level maintained free of foliage to ease the management, $w$ is the canopy width measured at breast height, $r$ is the distance between trees, and $n$ is the number of trees per hectare. Four measurements were taken per row. The vigor was further characterized by weighing the pruning wood of four trees per row during the winters of 2012 and 2014.

The ratio D/A of canopy depth $(h-t)$ to free alley width (i.e., the row spacing minus the hedgerow width $w$ ) was calculated to evaluate the canopy illumination (Connor and Gómez-delCampo, 2013).

\section{Flowering}

The flowering intensity was assessed by estimating the percentage of the canopy covered by inflorescences using a visual scale from 0 to 3, where 0 indicates no inflorescences; $1,=33 \%$; 2, 33-66\%; and $3,>66 \%$. This feature was evaluated at two heights (the upper and the lower half of the canopy) and in four trees per row during the 11th and 12th springs after planting. These estimates were later confirmed by evaluating the fruit distribution in the canopy.

\section{Statistical Analysis}

The effects of cultivar, tree density and year on the dependent variables-average annual fruit and oil yield ( $\mathrm{t}$ year ${ }^{-1} \mathrm{ha}^{-1}$ ), fruit weight (g), moisture (\%), and oil content (\%)-were examined using Friedman's test. This test was used because the data did not satisfy the requirements of parametric tests regarding normality, homogeneity of variance, or sphericity. The means were compared using Dunn's test with a Bonferroni adjustment at $P=0.05$ (Demšar, 2006). Analysis of variance (ANOVA) was performed on the accumulated fruit and oil production based on a randomized complete block design; subsequently, the means were compared using Tukey's test at
$P=0.05$. Linear regression was used to evaluate the relationships between the accumulated production (of fruit and oil) and the number of years after planting. Likewise, the variables for yield and for vigor (canopy volume and surface area) and the hedgerow length were regressed against tree density. Finally, we calculated the coefficient of determination $\left(R^{2}\right)$ and the coefficient of determination adjusted for degrees of freedom $\left(R^{2} a\right)$.

One-way repeated measures were used to analyze the olive vigor, $A B I$, and $B$ indexes because these data satisfied the sphericity requirement according to Mauchly's test. When appropriate, these data were transformed to be inverse or logarithmic. The flowering intensity and its distribution throughout the canopy were analyzed using a non-parametric Kruskal-Wallis test, after which Dunn's test $(P=0.05)$ was used to rank the cultivars based on their mean values. Statistical analyses were performed using Statistix software (Version 10; Statistix, Tallahassee, FL).

\section{RESULTS}

\section{Long-Term Evaluation of Olive Cultivars in SHD Systems}

Over 14 years, we monitored the relative performance of five olive cultivars that were widely used in SHD systems; in this study, the tree density was 1975 trees $\mathrm{ha}^{-1}$. During this period, the annual average fruit production of the cvs. "Arbequina," Arbequina IRTA-i.18, "Arbosana" and "Koroneiki" ranged from 12.2 to $14.2 \mathrm{t} \mathrm{ha}^{-1}$; there was no significantly difference in production $(P<0.05)$ between these cultivars (Supplementary Figure 1A; Table 1). In contrast, "Fs-17" consistently showed the lowest production, with yields approximately half as large as for the other cultivars $\left(6.2 \mathrm{tha}^{-1}\right)$.

Although there were no significant differences in average yield between the four most productive cultivars ("Arbequina," Arbequina IRTA-i-18, "Arbosana," and "Koroneiki"), we found significant differences in their accumulated fruit production (Supplementary Figure 1B; Table 1). The cv. "Arbosana" showed the largest accumulated fruit yield (170.1 $\left.\mathrm{t} \mathrm{ha}^{-1}\right)$, followed by Arbequina IRTA-i·18, "Arbequina" and "Koroneiki." There were significant differences $(P<0.05)$ between "Arbosana" and "Koroneiki" and between the cultivar "Fs-17" and all other cultivars $(P<0.001)$. This cultivar consistently had the lowest average as well as accumulated fruit production throughout the study period (Table 1).

Regarding the alternate bearing behavior of the cultivars, "Fs17 " also showed the most irregular production according to both the B and ABI indexes. "Arbequina" and Arbequina IRTA-i.18 had the most constant yields (Table 2). The information provided by the $\mathrm{ABI}$ and $\mathrm{B}$ indexes allowed us to rank the cultivars from greatest to least alternate bearing behavior as follows: "Fs$17 " \geq$ "Arbosana" = "Koroneiki" $\geq$ Arbequina IRTA-i.18 = "Arbequina” (Table 2).

"Fs-17" had the highest average fruit weight and moisture percentage (averaging $2.8 \mathrm{~g}$ and 59.9\%, respectively), while "Koroneiki" showed the lowest values for these variables 
TABLE 1 | Annual ( $\mathrm{ha}^{-1}$ ), average ( $\mathrm{ha}^{-1}$ year $^{-1}$ ), and accumulated ( $\mathrm{t} \mathrm{ha}{ }^{-1}$ ) fruit yield for the five evaluated olive cultivars growing in SHD conditions in southern Spain.

\begin{tabular}{|c|c|c|c|c|c|c|c|c|c|c|c|c|c|c|}
\hline \multirow[b]{2}{*}{ Cultivar } & \multicolumn{13}{|c|}{ Year after plantation/harvest season } & \multirow[b]{2}{*}{$\begin{array}{l}\text { Accumulated } \\
\left.\text { (t ha }^{-1}\right)\end{array}$} \\
\hline & $\begin{array}{c}3 \\
2002 / 03\end{array}$ & $\begin{array}{c}4 \\
03 / 04\end{array}$ & $\begin{array}{c}5 \\
04 / 05\end{array}$ & $\begin{array}{c}6^{a} \\
05 / 06\end{array}$ & $\begin{array}{c}7 \\
06 / 07\end{array}$ & $\begin{array}{c}8 \\
07 / 08\end{array}$ & $\begin{array}{c}9 \\
08 / 09\end{array}$ & $\begin{array}{c}10 \\
09 / 10\end{array}$ & $\begin{array}{c}11 \\
10 / 11\end{array}$ & $\begin{array}{c}12 \\
11 / 12\end{array}$ & $\begin{array}{c}13^{b} \\
12 / 13\end{array}$ & $\begin{array}{c}14 \\
13 / 14\end{array}$ & $\begin{array}{c}\text { Average } \\
\left(\mathrm{t} \mathrm{ha}^{-1} \text { year }^{-1}\right)\end{array}$ & \\
\hline Arbequina $\mathrm{i}-18$ & 14.8 & 14.0 & 20.1 & 6.2 & 8.5 & 13.2 & 9.6 & 10.3 & 16.0 & 15.1 & 7.2 & 22.8 & $13.2 \mathrm{a}$ & 157.9ab \\
\hline "Arbosana" & 17.2 & 9.0 & 19.4 & 7.4 & 17.4 & 9.0 & 15.3 & 10.8 & 20.4 & 15.0 & 10.6 & 18.7 & $14.2 \mathrm{a}$ & $170.1 \mathrm{a}$ \\
\hline "Arbequina" & 16.6 & 17.2 & 21.6 & 6.3 & 8.0 & 9.9 & 10.5 & 10.9 & 15.3 & 13.3 & 8.9 & 19.4 & $13.1 \mathrm{a}$ & $157.8 a b$ \\
\hline "Koroneiki" & 20.7 & 6.1 & 12.5 & 4.5 & 14.8 & 10.1 & 13.6 & 8.6 & 20.1 & 9.9 & 9.1 & 16.5 & $12.2 a$ & $146.6 \mathrm{~b}$ \\
\hline "Fs-17" & 4.4 & 2.8 & 8.8 & 0.7 & 10.9 & 4.6 & 7.8 & 4.0 & 14.4 & 5.1 & 7.2 & 3.8 & $6.2 b$ & $74.4 \mathrm{C}$ \\
\hline Average $^{c}$ & $14.7 a b$ & $9.8 \mathrm{bc}$ & $16.5 a b$ & $5.0 \mathrm{c}$ & 11.9abc & 9.3abc & 11.4abc & $8.9 a b c$ & $17.2 \mathrm{a}$ & $11.7 \mathrm{abc}$ & $8.6 b c$ & 16.2ab & & \\
\hline
\end{tabular}

a Severe frosts during the winter affected the tree growth.

${ }^{b}$ High temperatures $\left(>30^{\circ} \mathrm{C}\right)$ during the bloom period affected the fruit set.

${ }^{c}$ Means with the same letter are not significantly different according to Friedman test followed by Dunn's comparison adjusted by Bonferroni at $P=0.05$.

${ }^{d}$ Means with the same letter are not significantly different according to ANOVA followed by Tukey test at $P=0.05$.

TABLE 2 | Fruit characteristics, alternate bearing and vigor indexes for the five evaluated olive cultivars growing in SHD conditions in southern Spain during 14 years.

\begin{tabular}{|c|c|c|c|c|c|}
\hline Cultivar & "Arbosana" & "Arbequina" & Arbequina i-18 & "Koroneiki" & "Fs-17" \\
\hline Fruit weight (g) & $1.7 \mathrm{~b}$ & $1.8 b$ & $1.8 b$ & $1.1 \mathrm{C}$ & $2.8 a$ \\
\hline Fruit moisture (\%) & $58.0 \mathrm{~b}$ & $57.9 b$ & $58.4 a b$ & $55.0 c$ & $59.9 a$ \\
\hline Oil content ${ }^{\star}(\%)$ & $17.8 \mathrm{~b}$ & $17.3 b$ & $17.6 b$ & $18.8 \mathrm{a}$ & $18.8 \mathrm{a}$ \\
\hline$\left.A B\right|^{a c}$ & $0.30 \mathrm{~b}$ & $0.20 c$ & $0.23 c$ & $0.33 b$ & $0.47 a$ \\
\hline $\mathrm{B}^{\mathrm{b}}$ & $0.90 \mathrm{ab}$ & $0.58 d$ & $0.67 \mathrm{~cd}$ & $0.85 \mathrm{bc}$ & $0.95 a$ \\
\hline Tree height (m) & 3.9 & 4.2 & 4.3 & 4.1 & 3.9 \\
\hline Tree width (m) & 1.7 & 1.8 & 1.8 & 1.8 & 2.0 \\
\hline Canopy volume $\left(\mathrm{m}^{3} \mathrm{ha}^{-1}\right) \times 10^{3}$ & $14.1 \mathrm{c}$ & $16.8 \mathrm{a}$ & $16.8 \mathrm{a}$ & $15.9 b$ & 16.3ab \\
\hline External surface $\left(\mathrm{m}^{2} \mathrm{ha}^{-1}\right) \times 10^{3}$ & $21.0 c$ & $23.0 \mathrm{a}$ & $23.4 a$ & $22.2 b$ & $21.7 \mathrm{bc}$ \\
\hline Pruning wood $\left(\mathrm{t} \mathrm{ha}^{-1}\right)$ & $10.5 b$ & $17.6 a$ & $15.5 a$ & $14.2 \mathrm{a}$ & $17.4 \mathrm{a}$ \\
\hline Canopy depth/free alley (D/A) & 1.7 & 2.0 & 2.0 & 1.9 & 2.0 \\
\hline
\end{tabular}

${ }^{\star}$ Fresh weight.

${ }^{a}$ Alternate bearing index (ABI) from the 3rd to the 14th year after planting, which was calculated according to Pearce and Doberšek-Urbanc (1967).

${ }^{b}$ Bienniality index (B) from the 3rd to the 14th year after planting, which was calculated according to Monselise and Goldschmidt (1982).

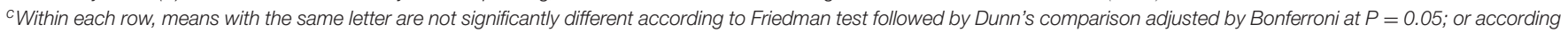
to one-way repeated measures followed by Tukey's test at $P=0.05$. No letter was added to any value when no significantly different pairwise comparisons were detected.

(averaging $1.1 \mathrm{~g}$ and $55.0 \%$, respectively). The remaining cultivars formed a homogenous group between these two endpoints (Table 2). "Fs-17" and "Koroneiki" consistently had the highest oil contents (both averaging 18.8\%), while "Arbequina," Arbequina IRTA-i.18 and "Arbosana" had lower values (17.3-17.8\%) with no significant differences between them (Friedman test; $P>0.05$; Table 2).

There were no significant differences in average oil production between cultivars, with the exception of "Fs-17," which had the lowest average production (Supplementary Figure 1C; Table 3). In terms of accumulated oil yield, "Arbosana" was the most productive cultivar, followed by "Koroneiki," Arbequina IRTAi.18, and "Arbequina" (Supplementary Figure 1D; Table 3). For this variable, there were significant differences between "Arbosana" and both Arbequina IRTA-i-18 and "Arbequina" (Friedman test; $P<0.05$ ). The oil yield of "Koroneiki" was intermediate and showed no significant differences compared to “Arbosana," Arbequina IRTA-i-18 or "Arbequina” (Table 3).

The accumulated fruit and oil production of the five cultivars increased linearly over time $\left(R^{2}>0.85 ; P<0.001\right.$; Supplementary Figures 1B,D; Tables 1, 3). Thus, we did not observe any decrease in the annual average production of oil for any cultivar over the 14 years of evaluation. However, when we evaluated the distribution of the crop in the hedgerows, we determined that it was consistently concentrated in the upper half of the canopy for all five cultivars (Kruskal-Wallis test; $P<0.05$; Table 4A). This feature was assessed by estimating the distribution of the flowers in the canopy and later confirmed based on the fruit distribution. The D/A values were $\sim 2$ for all the cultivars; "Arbosana" had the lowest value, with $\mathrm{D} / \mathrm{A}=1.7$ (Table 2). 
TABLE 3 | Annual ( $\left(\mathrm{ha}^{-1}\right)$, average ( $\left.\mathrm{ha}^{-1} \mathrm{year}^{-1}\right)$, and accumulated $\left(\mathrm{t} \mathrm{ha}^{-1}\right.$ ) oil yield for the five evaluated olive cultivars growing in SHD in southern Spain.

\begin{tabular}{|c|c|c|c|c|c|c|c|c|c|c|c|c|c|c|}
\hline \multicolumn{15}{|c|}{ Year after plantation/harvest season } \\
\hline Cultivar & $\begin{array}{c}3 \\
2002 / 03\end{array}$ & $\begin{array}{c}4 \\
03 / 04\end{array}$ & $\begin{array}{c}5 \\
04 / 05\end{array}$ & $\begin{array}{c}6^{a} \\
05 / 06\end{array}$ & $\begin{array}{c}7 \\
06 / 07\end{array}$ & $\begin{array}{c}8 \\
07 / 08\end{array}$ & $\begin{array}{c}9 \\
08 / 09\end{array}$ & $\begin{array}{c}10 \\
09 / 10\end{array}$ & $\begin{array}{c}11 \\
10 / 11\end{array}$ & $\begin{array}{c}12 \\
11 / 12\end{array}$ & $\begin{array}{c}13^{b} \\
12 / 13\end{array}$ & $\begin{array}{c}14 \\
13 / 14\end{array}$ & $\begin{array}{c}\text { Average }^{\mathrm{c}} \\
\left(\mathrm{t} \mathrm{ha}^{-1} \text { year }^{-1}\right)\end{array}$ & $\begin{array}{c}\text { Accumulated }{ }^{\mathrm{d}} \\
\left.\text { (t ha }^{-1}\right)\end{array}$ \\
\hline Arbequina i-18 & 2.6 & 2.0 & 2.9 & 1.3 & 1.9 & 2.8 & 1.9 & 2.0 & 2.5 & 2.7 & 1.1 & 3.3 & $2.2 a$ & $26.8 b$ \\
\hline "Arbosana" & 2.8 & 1.7 & 4.3 & 1.4 & 3.4 & 1.9 & 2.6 & 2.1 & 3.2 & 2.3 & 1.5 & 2.8 & $2.5 a$ & $29.9 a$ \\
\hline "Arbequina" & 2.5 & 2.5 & 3.0 & 1.3 & 1.7 & 2.2 & 2.2 & 2.1 & 2.5 & 2.3 & 1.4 & 2.9 & $2.2 \mathrm{a}$ & $26.3 b$ \\
\hline "Koroneiki" & 3.8 & 1.1 & 2.6 & 0.9 & 3.1 & 2.2 & 2.8 & 1.7 & 3.3 & 1.9 & 1.5 & 2.6 & $2.3 a$ & 27.3ab \\
\hline "Fs-17" & 0.7 & 0.4 & 1.3 & 0.2 & 2.3 & 1.1 & 1.9 & 0.9 & 2.4 & 1.0 & 1.2 & 0.6 & $1.2 \mathrm{~b}$ & $13.9 \mathrm{c}$ \\
\hline Average $^{\mathrm{C}}$ & $2.4 a b c$ & $1.5 \mathrm{bcd}$ & $2.8 \mathrm{a}$ & $1.0 d$ & $2.4 \mathrm{abc}$ & 2.0abcd & 2.3abcd & 1.8abcd & $2.8 a b$ & 2.0abcd & $1.3 \mathrm{~cd}$ & $2.4 \mathrm{abc}$ & & \\
\hline
\end{tabular}

a Severe frosts during the winter affected the tree growth.

${ }^{b}$ High temperatures $\left(>30^{\circ} \mathrm{C}\right)$ during the bloom period affected the fruit set.

${ }^{c}$ Means with the same letter are not significantly different according to Friedman test followed by Dunn's comparison adjusted by Bonferroni at $P=0.05$.

${ }^{d}$ Means with the same letter are not significantly different according to ANOVA following of Tukey test at $P=0.05$.

TABLE 4 | Differences in flowering intensity between the upper and the lower half of the tree canopy for the five evaluated cultivars (A) and the cv. "Arbequina" at nine tree densities (B). Flowering intensity was assessed by estimating the percentage of the canopy covered by inflorescences using a visual scale from 0 to 3 .

(A) Flowering intensity

$$
\text { Cultivars }
$$

\begin{tabular}{|c|c|c|c|c|c|}
\hline & & & & & \\
\hline & Arbequina i-18 & "Arbequina" & "Arbosana" & "Fs-17" & "Koroneiki" \\
\hline Lower canopy & $1.0 b \pm 0.08$ & $0.8 b \pm 0.10$ & $1.2 b \pm 0.05$ & $0.8 b \pm 0.11$ & $1.1 b \pm 0.08$ \\
\hline
\end{tabular}

\begin{tabular}{lccccccccc}
\hline (B) Flowering intensity & \multicolumn{8}{c}{ Density (trees ha $\mathbf{~}^{-1}$ ) } \\
\cline { 2 - 9 } & $\mathbf{7 8 0}$ & $\mathbf{9 0 9}$ & $\mathbf{9 5 2}$ & $\mathbf{1 1 4 3}$ & $\mathbf{1 2 0 3}$ & $\mathbf{1 4 8 1}$ & $\mathbf{1 5 6 9}$ & $\mathbf{2 0 0 0}$ & $\mathbf{2 2 5 4}$ \\
\hline Upper canopy & $1.7 \mathrm{a} \pm 0.21$ & $1.5 \mathrm{a} \pm 0.19$ & $1.9 \mathrm{a} \pm 0.17$ & $1.7 \mathrm{a} \pm 0.16$ & $1.7 \mathrm{a} \pm 0.17$ & $1.5 \mathrm{a} \pm 0.13$ & $1.6 \mathrm{a} \pm 0.21$ & $1.4 \mathrm{a} \pm 0.19$ & $1.8 \mathrm{a} \pm 0.28$ \\
Lower canopy & $1.5 \mathrm{a} \pm 0.26$ & $0.8 \mathrm{a} \pm 0.20$ & $1.0 \mathrm{~b} \pm 0.23$ & $1.1 \mathrm{a} \pm 0.21$ & $1.2 \mathrm{~b} \pm 0.14$ & $1.0 \mathrm{~b} \pm 0.22$ & $0.8 \mathrm{~b} \pm 0.22$ & $0.8 \mathrm{~b} \pm 0.14$ & $0.9 \mathrm{~b} \pm 0.17$ \\
$P$-value & 0.455 & 0.056 & $0.015^{\star}$ & 0.057 & $0.036^{\star}$ & $0.046^{\star}$ & $0.0394^{\star}$ & $0.0473^{\star}$ & $0.023^{\star}$ \\
\hline
\end{tabular}

*Significant differences according to a Kruskal-Wallis Test $(P<0.05)$.

We also compared the vigor of the olive cultivars. "Arbosana" was significantly $(P<0.05)$ more compact in shape, followed by "Fs-17" and "Koroneiki." In contrast, "Arbequina" and Arbequina IRTA-i.18 had the highest canopy volumes and surface areas. To further characterize the vigor of the cultivars in SHD systems, we weighed the pruned wood in two years. The results showed that "Arbosana" produced $10.5 \mathrm{t} \mathrm{ha}^{-1}$ of pruning wood while the rest of the cultivars produced between 14.2 and $17.6 \mathrm{t} \mathrm{ha}^{-1}$, with no significant differences between the cultivars $(P>0.05)$. In other words, "Arbosana" produced $\sim 35 \%$ less pruning wood than the other cultivars (Table 2).

\section{Effects of Tree Density on the Long-Term Performance of the "Arbequina" Cultivar}

To assess the optimum hedgerow spacing in SHD olive orchards, we evaluated the performance of the cv. "Arbequina" to nine plantation densities ranging from 780 to 2254 trees ha $^{-1}$ over 14 years. During this time, the fruit characteristics of "Arbequina" were stable and were not affected $(P>0.05)$ by the tree density. Regardless of the number of trees per ha, the average fruit weight was $\sim 1.95 \mathrm{~g}$, the moisture was around $57 \%$, and the oil content relative to fresh weight was $\sim 19 \%$ (Table 5).

The average annual production increased linearly with the tree density, ranging from 7.1 to $12.9 \mathrm{tha}^{-1}$ for fruit and from 1.3 to $2.5 \mathrm{t} \mathrm{ha}^{-1}$ for oil yield (Supplementary Figures 2A,C; Table 6). Consequently, the accumulated production increased over time as a function of tree density, and the relationship significantly fit a linear regression $\left(R^{2}>0.85 ; P<0.001\right.$; Table 6; Supplementary Figures $2 \mathrm{~B}, \mathrm{D})$. Differences in tree density accounted for up to $86 \%$ of the accumulated oil production per ha during the study period; the accumulated oil yield ranged from $16.1 \mathrm{t} \mathrm{ha}^{-1}$ for the lowest density ( 780 trees ha ${ }^{-1}$ ) to $29.9 \mathrm{tha}^{-1}$ for the highest (2254 trees ha ${ }^{-1}$; Table 6). The flowers-and therefore the crop-were consistently concentrated in the upper half of the canopy for all plantation densities (Kruskal-Wallis test; $P<0.05$; Table 4B), 
TABLE 5 | Fruit characteristics and alternate bearing and vigor indexes for "Arbequina" at nine densities in southern Spain during14 years.

\begin{tabular}{|c|c|c|c|c|c|c|c|c|c|}
\hline Density (trees ha-1) & 780 & 909 & 952 & 1143 & 1203 & 1481 & 1569 & 2000 & 2254 \\
\hline Fruit weight (g) & 1.9 & 2.1 & 2.0 & 1.9 & 1.9 & 1.9 & 1.9 & 2.2 & 2 \\
\hline Fruit moisture (\%) & 57.4 & 56.6 & 57.1 & 57.0 & 57.5 & 57.1 & 57.1 & 57.2 & 56.9 \\
\hline Oil content*(\%) & 18.8 & 19.1 & 19.3 & 19.3 & 19.1 & 19.1 & 19.1 & 19.2 & 19.1 \\
\hline$\left.A B\right|^{a c}$ & $0.20 \mathrm{ab}$ & $0.20 \mathrm{ab}$ & $0.18 \mathrm{bc}$ & $0.18 \mathrm{bc}$ & $0.20 \mathrm{ab}$ & $0.23 a$ & $0.19 a b$ & $0.17 \mathrm{bc}$ & $0.14 \mathrm{c}$ \\
\hline $\mathrm{B}^{\mathrm{b}}$ & 0.70 & 0.70 & 0.70 & 0.70 & 0.70 & 0.80 & 0.67 & 0.72 & 0.72 \\
\hline Tree height (m) & 3.8 & 3.9 & 4.0 & 4.0 & 3.9 & 4.0 & 4.0 & 4.1 & 4.2 \\
\hline Tree width (m) & 1.9 & 1.9 & 2.0 & 1.9 & 1.9 & 1.8 & 1.8 & 1.8 & 1.9 \\
\hline Tree volume $\left(\mathrm{m}^{3}\right.$ tree $\left.^{-1}\right)$ & $13.1 \mathrm{a}$ & $11.9 b$ & $12.6 \mathrm{ab}$ & $10.7 c$ & $10.1 c$ & $8.9 d$ & $9 d$ & $7.6 e$ & $7.9 \mathrm{e}$ \\
\hline Hedgerow volume $\left(\mathrm{m}^{3} \mathrm{ha}^{-1}\right) \times 10^{3}$ & $10.2 f$ & $10.8 f$ & $12 e$ & $12.2 e$ & $12.1 \mathrm{e}$ & $13.2 d$ & $14.2 \mathrm{c}$ & $15.2 b$ & $17.8 \mathrm{a}$ \\
\hline External hedgerow surface $\left(\mathrm{m}^{2} \mathrm{ha}^{-1}\right) \times 10^{3}$ & $14.1 \mathrm{~g}$ & $14.7 \mathrm{~g}$ & $15.9 f$ & $16.7 e$ & $16.9 e$ & $18.4 d$ & $19.8 c$ & $21.3 b$ & $24.3 a$ \\
\hline Pruning waste (t ha ${ }^{-1}$ ) & 10.5 & 11.9 & 12.0 & 13.2 & 13.7 & 16.3 & 14.8 & 15.4 & 14.8 \\
\hline Row space (m) & 5.7 & 5.5 & 5.2 & 5.0 & 4.7 & 4.5 & 4.2 & 4.0 & 3.5 \\
\hline Canopy depth/free alley (D/A) & 0.9 & 1.0 & 1.1 & 1.2 & 1.2 & 1.4 & 1.6 & 1.8 & 2.3 \\
\hline
\end{tabular}

${ }^{\star}$ Fresh weight.

${ }^{a}$ Alternate bearing index (ABI) from the 3rd to the 14th year after planting, which was calculated according to Pearce and Doberšek-Urbanc (1967).

${ }^{b}$ Bienniality index (B) from the 3rd to the 14th year after planting, which was calculated according to Monselise and Goldschmidt (1982).

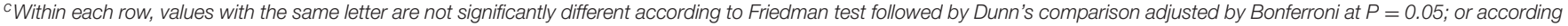

to one-way repeated measures followed by Tukey's test at $P=0.05$. No letter was added to any value when no significantly different pairwise comparisons were detected.

with the exception of the two lowest densities (708 and 909 trees $\mathrm{ha}^{-1}$ ) and 1143 trees $\mathrm{ha}^{-1}$. The two lowest densities were the only ones that showed $\mathrm{D} / \mathrm{A} \leq 1$ (Table 5 ).

Remarkably, we did not detect any progressive decrease in annual production over the study period for any of the density treatments (Table 6). The variability in yield between consecutive years was primarily due to the biennial cycle of the "Arbequina" cultivar. The most dramatic variations occurred in response to climatic stresses such as frost (in 2004-2005 and 2011-2012) and unusually elevated temperatures during bloom time (in 2012; Table 5). The alternate bearing behavior of "Arbequina" was not correlated with tree density (Table 5); neither the ABI nor the B indices had a significant relationship with tree density (Table 5). For instance, the highest density treatment, with 2254 trees ha $^{-1}$, had the lowest ABI (0.14) and therefore weaker alternate bearing behavior. In contrast, the lowest density treatment, with 780 trees $\mathrm{ha}^{-1}$, showed an intermediate ABI value (0.20), and the intermediate treatment with 1481 trees $\mathrm{ha}^{-1}$ had the largest $\mathrm{ABI}(0.23)$ and therefore the strongest alternate bearing behavior (Table 5).

The vigor (measured as canopy volume) and the yield per tree were negatively linearly correlated with the tree density (Figures 1A,B; Table 5). In contrast, the hedgerow volume, surface area, and production per hectare showed the opposite trend, increasing with tree density (Figures 1C,D; Table 5). Comparing the lowest and highest density treatments (780 and 2254 trees $\mathrm{ha}^{-1}$ ) showed that the volume of the trees decreased by $\sim 40 \%$ while the volume and the external surface of the hedgerow increased by $\sim 75$ and $72 \%$, respectively (Table 5). The pruning waste per hectare increased with tree density but only until intermediate tree densities (1481 trees ha ${ }^{-1}$ ), after which it remained stable, with a value close to $15 \mathrm{t} \mathrm{ha}^{-1}$ (Table 5).

\section{DISCUSSION}

\section{Long-Term Evaluation of Olive Cultivars in SHD Systems}

Since the inception of SHD olive orchards, there has been controversy regarding their management, productivity, lifespan, and profitability. In recent years, several studies have examined these features; however, they largely focused on young SHD olive orchards, given the recent popularity of these systems (Hermoso et al., 2004; Pastor et al., 2007; Camposeo and Godini, 2010; Larbi et al., 2011, 2012; Connor et al., 2012; Farinelli and Tombesi, 2015; Trentacoste et al., 2015a). Thus, no long-term characterizations of olive SHD orchards have been published. To address this gap in knowledge, we characterized the performance of various olive cultivars and the most frequent SHD plantation designs in field trials that lasted 14 years. The trials were located in the world's main olive-producing region, Andalusia, in southern Spain.

Over the study period, we evaluated the performance of three traditional olive cultivars commonly used in SHD systems, "Arbequina," “Arbosana," and "Koroneiki," along with the popular clonal selection Arbequina IRTA-i.18 (Tous et al., 1998) and the new olive cultivar "Fs-17" (Fontanazza et al., 1998).

Seven years after planting, the preliminary results of these trials highlighted the early bearing of the cultivars in the study, with the exception of "Fs-17." In addition, these results emphasized their high oil yields and showed subtle differences between the oil content and alternate bearing behavior of the various cultivars. The study also noted the stability and cultivarspecificity of the fatty acid profiles of the oils, which did not vary significantly between years (De la Rosa et al., 2007). Most of these early observations were later supported by other studies of young 
TABLE 6 | Annual (t ha-1), average ( $\mathrm{t} \mathrm{ha}^{-1}$ year $\left.^{-1}\right)$, and accumulated $\left(\mathrm{t} \mathrm{ha}^{-1}\right)$ fruit and olive yield for "Arbequina" at nine densities 14 years after planting in southern Spain.

\begin{tabular}{|c|c|c|c|c|c|c|c|c|c|c|c|c|c|c|c|}
\hline \multicolumn{16}{|c|}{ Year after plantation/harvest season } \\
\hline & $\begin{array}{l}\text { Density } \\
\left.\text { (Trees ha }^{-1}\right)\end{array}$ & $\begin{array}{c}3 \\
2002 / 2003\end{array}$ & $\begin{array}{c}4 \\
03 / 04\end{array}$ & $\begin{array}{c}5 \\
04 / 05\end{array}$ & $\begin{array}{c}6 \\
05 / 06\end{array}$ & $\begin{array}{c}7 \\
06 / 07\end{array}$ & $\begin{array}{c}8 \\
07 / 08\end{array}$ & $\begin{array}{c}9 \\
08 / 09\end{array}$ & $\begin{array}{c}10 \\
09 / 10\end{array}$ & $\begin{array}{c}11 \\
10 / 11\end{array}$ & $\begin{array}{c}12 \\
11 / 12\end{array}$ & $\begin{array}{c}13 \\
12 / 13\end{array}$ & $\begin{array}{c}14 \\
13 / 14\end{array}$ & $\begin{array}{c}\text { Average }^{\text {c }} \\
\left(\mathrm{t} \mathrm{ha}^{-1}\right. \\
\left.\text { year }^{-1}\right)\end{array}$ & $\begin{array}{c}\text { Accumulated }^{\mathrm{d}} \\
\left.\text { (t ha }^{-1}\right)\end{array}$ \\
\hline \multirow[t]{10}{*}{ Fruit (t ha-1) } & 780 & 5.8 & 3.9 & 6.9 & 6.3 & 5.6 & 7.3 & 6.5 & 5.9 & 8.6 & 8.9 & 5.5 & 13.6 & $7.1 d$ & $84.8 \mathrm{e}$ \\
\hline & 909 & 6.8 & 3.6 & 7.9 & 6.9 & 6.1 & 7.3 & 7.9 & 6.8 & 7.7 & 8.9 & 5.5 & 14.9 & $7.5 d$ & $90.3 e$ \\
\hline & 952 & 7.0 & 4.9 & 8.8 & 7.2 & 6.8 & 8.9 & 7.5 & 6.2 & 8.7 & 9.6 & 5.5 & 13.8 & $7.9 \mathrm{~cd}$ & 95.0de \\
\hline & 1143 & 8.1 & 4.9 & 9.6 & 8.0 & 7.3 & 7.9 & 7.7 & 7.3 & 9.7 & 10.6 & 5.9 & 15.3 & $8.5 \mathrm{bcd}$ & $102.4 \mathrm{~cd}$ \\
\hline & 1203 & 7.5 & 5.7 & 9.6 & 7.3 & 6.8 & 11.4 & 8.5 & 8.5 & 11.2 & 10.3 & 5.0 & 16.3 & $9.0 \mathrm{bcd}$ & 108.0c \\
\hline & 1481 & 9.0 & 6.6 & 10.7 & 9.0 & 7.9 & 10.3 & 7.6 & 7.3 & 11.8 & 11.6 & 4.2 & 16.9 & $9.4 \mathrm{abc}$ & 113.0c \\
\hline & 1569 & 8.8 & 8.0 & 11.9 & 8.9 & 7.7 & 12.1 & 11.0 & 8.5 & 13.6 & 12.8 & 7.0 & 16.9 & 10.6ab & $127.2 b$ \\
\hline & 2000 & 10.9 & 9.3 & 12.0 & 9.0 & 9.3 & 11.7 & 11.0 & 9.8 & 16.1 & 10.4 & 7.7 & 18.8 & 11.3ab & $135.9 b$ \\
\hline & 2254 & 10.4 & 8.3 & 14.4 & 11.1 & 10.9 & 12.1 & 12.2 & 10.5 & 17.9 & 15.3 & 10.6 & 21.4 & $12.9 a$ & $155.0 \mathrm{a}$ \\
\hline & Average & $8.3 e$ & $6.1 \mathrm{bcde}$ & 10.2abc & 8.2bcde & 7.6de & 9.9abcd & 8.9abcde & $7.9 \mathrm{cde}$ & 11.7ab & 10.9ab & $6.3 e$ & $16.4 a$ & & \\
\hline \multirow[t]{10}{*}{ Oil (t ha-1) } & 780 & 0.9 & 0.8 & 1.2 & 1.3 & 1.3 & 1.6 & 1.4 & 1.2 & 1.4 & 1.7 & 0.9 & 2.3 & $1.3 d$ & $16.1 \mathrm{f}$ \\
\hline & 909 & 1.1 & 0.7 & 1.5 & 1.5 & 1.4 & 1.6 & 1.7 & 1.4 & 1.2 & 1.7 & 0.9 & 2.5 & $1.4 \mathrm{~cd}$ & 17.4ef \\
\hline & 952 & 1.2 & 1.0 & 1.8 & 1.5 & 1.5 & 2.0 & 1.6 & 1.2 & 1.4 & 1.8 & 0.9 & 2.3 & $1.5 \mathrm{~cd}$ & 18.4de \\
\hline & 1143 & 1.4 & 1.1 & 1.8 & 1.8 & 1.7 & 1.7 & 1.6 & 1.4 & 1.6 & 2.0 & 0.9 & 2.7 & $1.6 b c d$ & $19.8 \mathrm{~cd}$ \\
\hline & 1203 & 1.2 & 1.2 & 2.1 & 1.5 & 1.4 & 2.4 & 1.8 & 1.7 & 1.8 & 1.9 & 0.8 & 2.7 & $1.7 \mathrm{bcd}$ & $20.5 \mathrm{~cd}$ \\
\hline & 1481 & 1.5 & 1.4 & 2.1 & 1.9 & 1.8 & 2.2 & 1.5 & 1.5 & 1.9 & 2.1 & 0.7 & 2.7 & $1.8 \mathrm{bc}$ & $21.7 c$ \\
\hline & 1569 & 1.4 & 1.8 & 2.1 & 1.9 & 1.8 & 2.6 & 2.3 & 1.7 & 2.2 & 2.4 & 1.1 & 2.7 & 2.0ab & $24.1 b$ \\
\hline & 2000 & 1.6 & 2.2 & 2.3 & 1.9 & 2.1 & 2.5 & 2.2 & 2.0 & 2.7 & 1.9 & 1.3 & 3.2 & $2.2 \mathrm{ab}$ & $26.0 b$ \\
\hline & 2254 & 1.6 & 1.9 & 2.5 & 2.4 & 2.6 & 2.7 & 2.5 & 2.1 & 3.1 & 2.9 & 1.8 & 3.6 & $2.5 a$ & $29.9 a$ \\
\hline & Average $^{C}$ & $1.3 \mathrm{ef}$ & 1.3def & 1.9abcd & 1.8bcdef & .7bcdef & $2.2 \mathrm{ab}$ & $1.8 a b c$ & $0<0$ & 1.9abcc & $2.1 \mathrm{abc}$ & $1.0 f$ & $2.8 \mathrm{a}$ & & \\
\hline
\end{tabular}

a Severe frosts during the winter affected the tree growth

${ }^{b}$ High temperatures $\left(>30^{\circ} \mathrm{C}\right)$ during the bloom period affected the fruit set.

${ }^{c}$ Means with the same letter are not significantly different according to Friedman test followed by Dunn's comparison adjusted by Bonferroni at $P=0.05$.

${ }^{d}$ Means with the same letter are not significantly different according to ANOVA followed by Tukey test at $P=0.05$.

SHD orchards (Camposeo and Godini, 2010; Godini et al., 2011; Larbi et al., 2011; Tous et al., 2011; Farinelli and Tombesi, 2015; Trentacoste et al., 2015a).

Our 14 year study is the first to demonstrate the favorable long-term adaptation of "Arbequina," Arbequina IRTA-i.18, "Arbosana" and "Koroneiki" in SHD systems. The 12 crops produced by these cultivars were highly productive, with an average oil yield of almost $2.3 \mathrm{t} \mathrm{ha}^{-1}$. More importantly, we note that their average production did not decrease over time. We also confirmed two early observations: first, the absence of significant difference between "Arbequina" and its clone selection Arbequina IRTA-i-18; and second, the different alternate bearing behaviors among the cultivars, with "Arbequina" and Arbequina IRTA-i.18 showing the most stable production, followed by "Arbosana," "Koroneiki," and "Fs-17." Few studies have focused on alternate bearing behavior of olive (Rallo et al., 1993; Lavee, 2006; Larbi et al., 2011), suggesting that it should be systematically evaluated. This fact is particularly striking given that the olive biennial bearing is, along with climatic stresses, the cause of the greatest differences in production between consecutive years.

\section{Relative Performance of the Cultivars}

The outstanding performance of "Arbosana" in SHD systems (Camposeo and Godini, 2010; Larbi et al., 2011; Tous et al., 2011; Rosati et al., 2013) is leading to its widespread use in orchards around the world, to the extent that it has begun to challenge "Arbequina" as the olive cultivar of choice for SHD systems. In our experiments, "Arbosana" and "Arbequina" had similar oil contents, but "Arbosana" had the largest accumulated oil yield $\left(29.9 \mathrm{t} \mathrm{ha}^{-1}\right) 14$ years after planting. "Arbosana" also had the lowest vigor, as determined based on the canopy volume and external canopy area; it produced $\sim 35 \%$ less pruning wood than "Arbequina." These two cultivars, but especially "Arbosana," coupled high productivity with a compact shape because of their higher branching efficiency, defined as the number of branches per unit of trunk cross-sectional area (Rosati et al., 2013). Branching frequency has been shown to be positively correlated with thinner bearing limbs, resulting in a larger number of potential fruiting sites per unit of trunk weight and thus higher yield efficiency (Rosati et al., 2013).

Despite their similarities, "Arbequina" and "Arbosana" differ greatly in their ripening time; "Arbequina" ripens in November, 

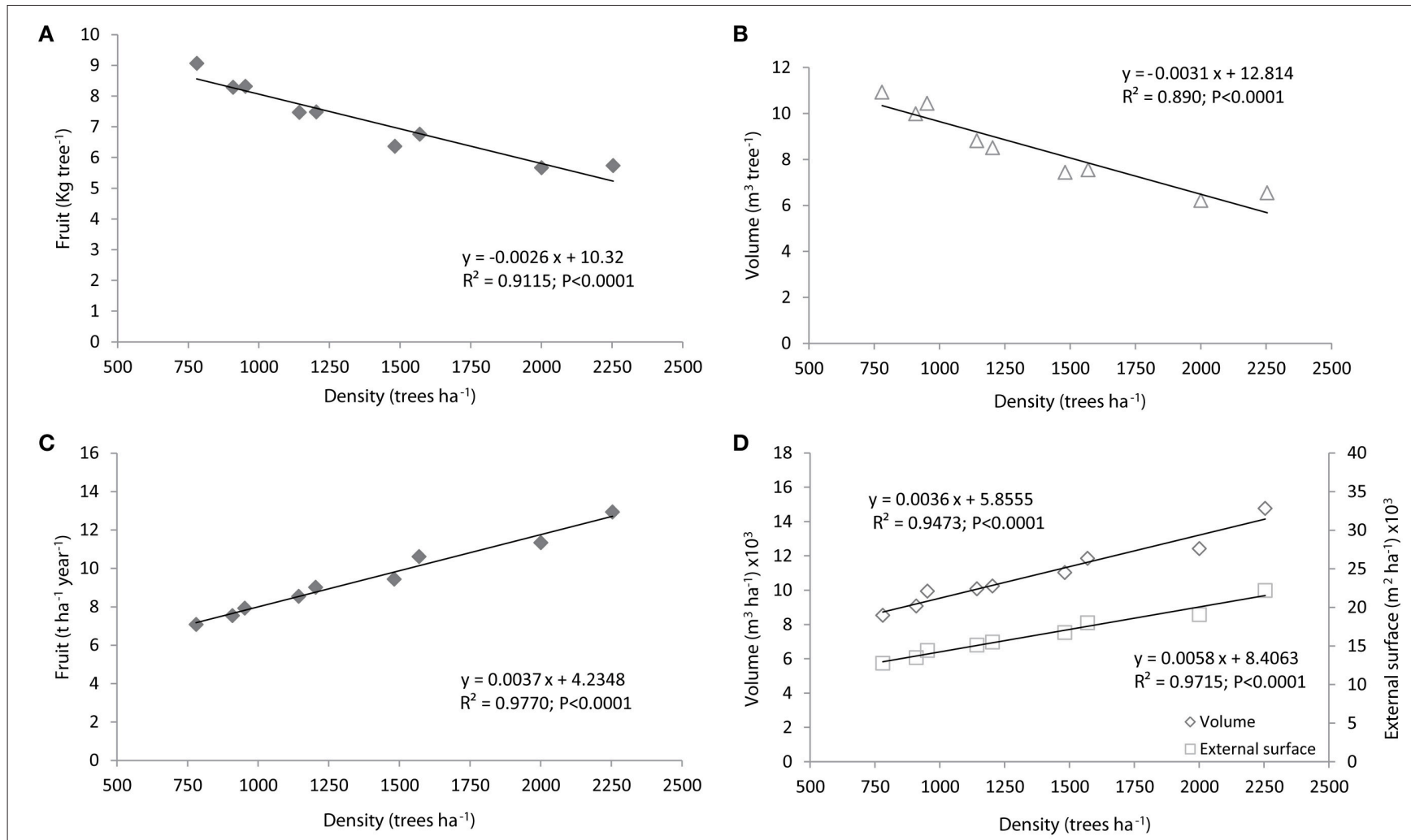

FIGURE 1 | The annual fruit production (A) and canopy volume (B) per tree are compared to the annual fruit production (C) and hedgerow surface and volume per hectare (D), both as functions of the olive tree density for the cultivar "Arbequina." Lines represent linear regression of the variables A, B, C, and D over tree density. The points represent the average values per olive tree or surface area of orchard over 14 years. Nine tree densities ranging from 780 to 2254 trees $\mathrm{ha}^{-1}$ were evaluated in this study.

while "Arbosana" ripens in January-February (Barranco et al., 2000, 2005). This feature should be taken into account when planting "Arbosana" in areas with winter frost occurrence because frost damage is especially severe when fruits are green-yellow (Barranco, 2010). In addition, to avoid frost damage, "Arbosana" is often harvested too early, before reaching its maximum oil content, and this can lead to lower than expected oil yields.

The cv. "Koroneiki" was also favorably adapted to SHD conditions in terms of yield. It produced as much accumulated oil as "Arbequina" even though its fruit production was lower. "Koroneiki" has been described as highly productive, with high oil content and low to medium vigor (Barranco et al., 2000). Field observations in commercial orchards have confirmed the higher vigor of "Koroneiki" hedgerows compared to "Arbequina" and "Arbosana." In addition, "Koroneiki" often presents vertical lignified top branches that are prone to damage during mechanical harvesting (Todolivo S.L, personal communication). Our characterization of the canopy volume and external surface did not reflect the higher vigor of "Koroneiki" observed in the field. In addition, the amount of pruning waste only distinguished the lower vigor of "Arbosana" compared to the rest of the cultivars. The assessment of cultivar vigor might not be trivial for fully-grown hedgerows because the tree height and width are determined by pruning (to fit the size of the straddle harvester, with a height of $\sim 2.7-3.0 \mathrm{~m}$ and a width of $1.3 \mathrm{~m}$ ) rather than by tree architecture. Thus, at this stage, it is likely that only large differences in vigor between cultivars (such as for "Arbosana") can be correctly assessed. We note that the pruning waste, which affects the entire tree, could be a more reliable proxy for adult hedgerow vigor than the tree height and width.

Finally, the generally favorable adaptation of "Arbequina," "Arbosana," and "Koroneiki" contrasted with the poor performance of "Fs-17." For instance, the average yield of "Fs-17" was half as large as that of the other cultivars, which agrees with Tous et al. (2008). High fruit production but substantial vigor and a spreading growth habit (which are not desirable features in SHD systems) were also previously reported for "Fs-17" (Camposeo and Godini, 2010). Although "Fs-17" had elevated oil content, these results suggest that "Fs-17" is not a suitable cultivar for SHD systems under the experimental conditions in this study.

We also note that in our study, "Fs-17" was highly susceptible to the fungus Alternaria alternata during a 2 year outbreak, while the remaining cultivars barely showed any symptoms of the disease (Moral et al., 2008). The microclimatic and agronomic conditions of SHD systems are highly conducive to airborne diseases. Thus, the differential resistance of the cultivars to major pests and diseases should also be taken into account when establishing an SHD orchard, especially in areas where 
Colletotrichum spp., the causal agent of olive anthracnose, is endemic (Moral et al., 2012). In addition, the numerous wounds in the branches caused by the mechanical harvester result in a greater risk of infections from wound-associated pathogens such as Botryosphaeriaceae species and the bacterium Pseudomonas savastanoi pv. savastanoi (Moral et al., 2010).

\section{Influence of Tree Density on the Long-Term Performance of the "Arbequina" Cultivar}

We planted olive hedgerows of the cultivar "Arbequina" at nine densities ranging from 780 to 2254 trees $\mathrm{ha}^{-1}$; we achieved these densities by reducing the row spacing from 5.7 to $3.55 \mathrm{~m}$ and the tree spacing from 2.25 to $1.25 \mathrm{~m}$. Preliminary results of this trial were reported 7 years after planting (León et al., 2007).

After 14 years of evaluation, two early observations were reinforced. First, the no influence of tree density on the characteristics of cv. "Arbequina," including the biennial bearing behavior and the fruit oil content, moisture and average weight. Larbi et al. (2012) also described that tree density did not affect the biennial bearing behavior and the fruit oil content of this cultivar. However, they reported a negative correlation between tree density and fruit size that was not observed in our study. Similarly, Trentacoste et al. (2015a) reported a slight negative correlation, which was only significant in one out of four crops in their study, between tree density and oil content that was not supported by our results and those obtained by Larbi et al. (2012). The effect of tree density on fruit quality could be variable and difficult to uncouple from the illumination problems associated with high tree densities; in apple trees, for example, the planting density has a relatively low influence on fruit quality (firmness, soluble solids, titratable acidity, or weight) although poor illumination affected the color of the fruits (Wagenmakers and Callesen, 1995; Widmer and Krebs, 2001). In olive trees, fruits developed under conditions of high light interception show different fatty acid and polyphenol profiles than fruits developed in the shade (Gómez-del-Campo and García, 2012; Connor and Gómez-del-Campo, 2013).

The second observation confirmed by this study was the persistence of the positive correlation between density and oil yield preliminary reported (León et al., 2007). In this study, the accumulated oil production per hectare significantly increased by $86 \%$ in the highest density treatment $\left(2254\right.$ trees $\left.\mathrm{ha}^{-1}\right)$ relative to the lowest density treatment (780 trees $\left.\mathrm{ha}^{-1}\right)$. Conversely, the accumulated oil production per tree decreased by $37 \%$. The canopy volume showed a similar inverse relationship, increasing by $75 \%$ per hectare but decreasing by $40 \%$ per tree in the highest and lowest density treatments, respectively. While this dynamic has been described in young SHD olive orchards and for other fruit crops, its persistence over the long term has been questioned for olives (Wagenmakers and Callesen, 1995; Wheaton et al., 1995; Widmer and Krebs, 2001; Hampson et al., 2004; Larbi et al., 2012; Trentacoste et al., 2015a). For instance, yield efficiency in apple trees began to decrease by the eighth year at high densities ( 3200 trees/ha; Hampson et al., 2004). Conversely, in citrus trees, there was no consistent relationship between yield and tree density for 9-13 year-old trees (Wheaton et al., 1995).
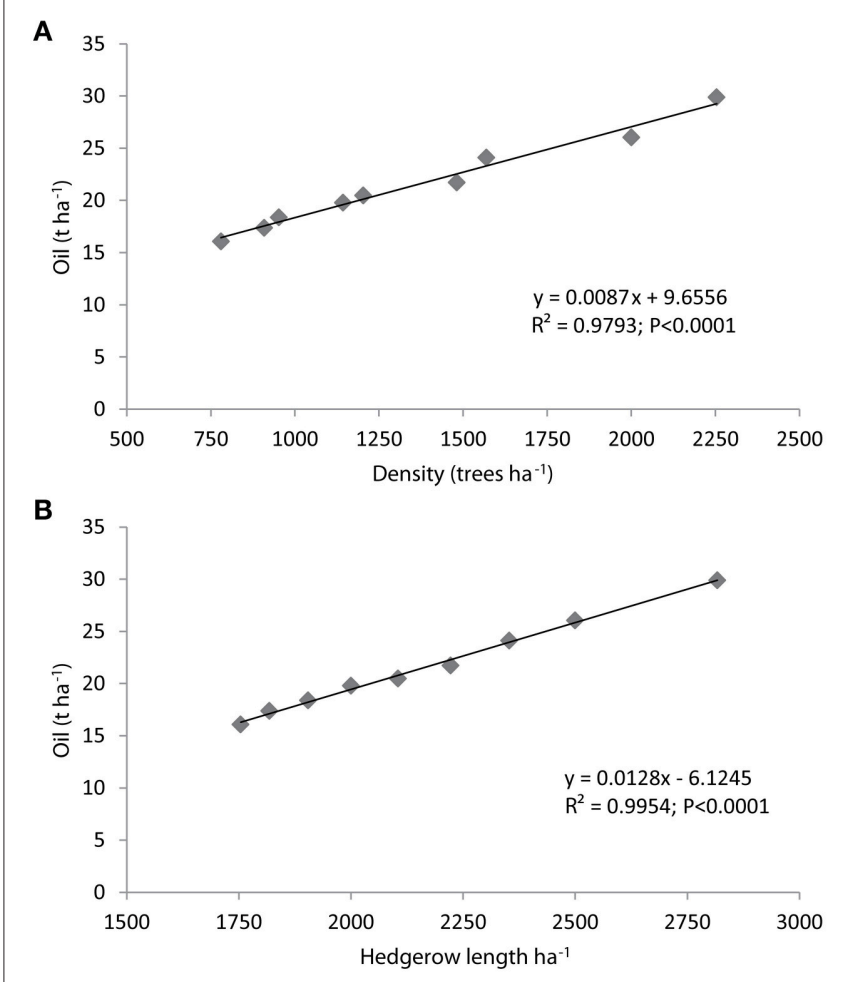

FIGURE 2 | Linear regression of accumulated oil per hectare over olive tree density $(A)$ or the hedgerow length $(B)$ over 14 years after planting the cultivar "Arbequina."

We noted that the accumulated production per surface unit was highly correlated with the tree density but even better with the hedgerow length $\left(R^{2}=0.9793\right.$ vs. $R^{2}=0.9954$; Figures 2A,B). In other words, the hedgerow length served as an accurate proxy of the accumulated yield of the adult hedgerows. This observation is especially remarkable given that the distance between trees does not affect the determination of the hedgerow length, which is basically determined by the row spacing. We hypothesize that if tree space is sufficiently reduced to rapidly lead to a solid hedgerow, the row spacing and therefore the length of the hedgerows will primarily determine the yield per ha. Trentacoste et al. (2015a) used the hedgerow length as a productive unit for SHD olive orchards; however, the tree spacing in their experiments was constant. In this study, the tree distance ranged from 1.25 to $2.25 \mathrm{~m}$, but it had no influence on the accumulated yield 14 years after planting.

\section{Productive Lifespan of Olive Hedgerows}

One of the most important results of this study was the no decrease in the average annual yield of the SHD olive orchards 14 years after planting. Regardless of the cultivar and the tree density, the accumulated production of the hedgerows linearly increased as a function of time. Our results contradict those of previous SHD field trials in the same geographical area that showed declines in production seven or eight years after planting due to high vigor, shading, and limited ventilation (Pastor et al., 
2007). The uncontrolled vigor of these hedgerows was probably due to their excessive irrigation dosage, which tripled the amount of water that was applied to our trials $\left(6000\right.$ vs. $2000 \mathrm{~m}^{3} \mathrm{ha}^{-1}$ year $^{-1}$ ). Likewise, excessive fertilization could have also fostered the vigor of the trees; however, we cannot assess this hypothesis since the fertilization program for this previous trial was not fully detailed. The determination of soil characteristics, fertility levels, as well as the monitoring of "unintentional" sources of nutrients, such that coming from nitrate-polluted irrigation water, are critical determinants for a rational orchard management. Indeed, in an optimal climate and soil environment, managing the amount of water and fertilizers applied are crucial to avoid vigor problems that can compromise the lifespan of the hedgerow (Rallo et al., 2013; Connor et al., 2014).

Although the annual production of our hedgerows did not decrease over the time, we observed that by the end of the study period, the yield was consistently distributed in the upper part of the canopy (Table 4). This irregular pattern of fruit distribution in olive and other fruit crops is often related to illumination problems in the lower canopy (Wheaton et al., 1995; Farina et al., 2005; Connor et al., 2012). The optimum illumination for olive hedgerows occurs when the canopy depth equals the free alley width (D/A = 1; Connor and Gómez-del-Campo, 2013). Above this value, shading problems generally arise and trigger the accumulation of the production in the upper part of the canopy (Pastor et al., 2007; Trentacoste et al., 2015a). This feature has been reported even for very young olive hedgerows with D/A > 1 (Trentacoste et al., 2015a). In our study, only the two lowest density treatments of "Arbequina" (780 and 909 trees ha $^{-1}$ ) and 1143 trees $\mathrm{ha}^{-1}$, with a row spacing $\geq 5 \mathrm{~m}$ and $\mathrm{D} / \mathrm{A} \sim 1$, showed a uniform distribution of the crop throughout the canopy. The only exception to this consistent pattern was "Arbequina" at 952 trees $\mathrm{ha}^{-1}$, which showed unequal distribution of the crop in the canopy with row spacing $>5 \mathrm{~m}$ and D/A $\sim 1$. Even "Arbosana," the cultivar with the lowest vigor, showed $\mathrm{D} / \mathrm{A}>1(\mathrm{D} / \mathrm{A}=1.7)$; hence, its production was concentrated in the upper part of the canopy.

The height of our hedgerows, which approached $4 \mathrm{~m}$ in all the treatments (cultivars and densities), could be the primary cause of this feature (Supplementary Figures $3 \mathrm{~A}, \mathrm{~B}$ ). The top branches were flexible enough not to be damaged by the straddle harvester, which worked at $2.6 \mathrm{~m}$ height (Supplementary Figures 3C,D). However, tall canopies mean that increasing proportions of the lower canopy receive little or no direct radiation, which is exacerbated by narrow alley width (Connor et al., 2012). The height of our hedgerows would require a minimum row spacing of $5.5 \mathrm{~m}$ to yield the optimum $\mathrm{D} / \mathrm{A}=1$, a requirement that was only fulfilled by the two lowest density treatments.

While the D/A ratio seems to be a good proxy for hedgerow illumination, our results raise several questions. First, it is unclear how quickly accumulation of the production in the upper half of the canopy becomes significant when illumination problems arise; second, if this process is modulated by cultivar architecture and vigor; third, whether specific management practices such as pruning or deficit irrigation could avoid or minimize the effects of insufficient illumination within the alleys; and fourth, if specific pruning strategies could reverse these effects once they become pervasive in the hedgerows.

Finally, it is difficult to reconcile the apparent illumination problems of our hedgerows with the lack of decrease in oil production per hectare over time (even for the highest density treatments). It is not clear why we did not observe a correlation between these factors, even under favorable conditions (D/A > 1). However, we suggest that three main factors could account for our observations: first, the row spacing in our trials, which ranged from 3.55 to $5.70 \mathrm{~m}$, was therefore not as restrictive as the $2.5 \mathrm{~m}$ evaluated by (Trentacoste et al., 2015a). Second, our study area had very good environmental conditions for the olive crop, which favored high yields; for example, the yields of "Arbosana" and "Koroneiki" in our study were almost twice as high as the average yields obtained in other locations (Camposeo and Godini, 2010; Larbi et al., 2011; Tous et al., 2011). Third, our pruning strategy was milder than in most other commercial hedgerows, which are heavily pruned to limit their height to $3 \mathrm{~m}$ to fit the straddle-harvester machine. Heavier pruning stimulates more vegetative growth and causes denser canopies and internal canopy shading, reducing fruiting capacity. Thus, it is possible that, due to our softer pruning, the upper canopy layers were able to compensate for the production of the layers with insufficient illumination. Tall hedgerows with narrow canopies have been proposed as promising orchards systems for apple tree in the near future (Robinson et al., 2013). In accord with this idea, there are pilot strategies in olive aimed to evaluate the combination of wider row spaces $(5-5.5 \mathrm{~m})$ and taller hedgerows $(>4 \mathrm{~m})$, given the progressive availability of harvesters able to straddle tall trees. These orchards represent lower initial costs because they have less hedgerow length per hectare, but also because of the same reason, lower production. However, it still needs to be evaluated whether taller hedgerows could be able to compensate this productive difference. Lastly, the remarkable inherent longevity and renovation capacity of olive trees compared to other fruit crops could contribute to this behavior. We note that Mediterranean agricultural landscapes are characterized by centuries-old, but still fully productive, olive orchards.

This study was the first to characterize the long-term performance of SHD olive hedgerows. However, additional comparative trials should be conducted in other geographical locations. This would allow us to establish general patterns and define optimal management strategies to ensure the long-term productivity of SHD olive orchards worldwide.

\section{AUTHOR CONTRIBUTIONS}

Conceived and designed the experiments: DB and LR. Performed the evaluations: CD, DC, PM. Analyzed the data: JM, DC, CD, and DB. Wrote the paper: CD, JM, LR, and DB.

\section{ACKNOWLEDGMENTS}

We thank the company Todolivo SL. its support, collaboration, and assistance in this research. JM holds a Talent Hub 
Post-Doc fellowship launched by the Andalusian Knowledge Agency and funded by the European Union's ( $7^{\text {th }} \mathrm{FP}$ ) and the Junta de Andalucía. We also thank the three reviewers for their helpful comments to improve the manuscript.

\section{REFERENCES}

Barranco, D. (2010). "Varieties and rootstocks," in Olive Growing, eds D. Barranco, R. Fernández-Escobar, and L. Rallo (Madrid: Junta de Andalucia and MundiPrensa), 59-82.

Barranco, D., Cimato, A., Fiorino, P., Rallo, L., Touzani, A., Castañeda, C., et al. (2000). World Olive Catalogue of Olive Varieties. Madrid: International Olive Council.

Barranco, D., Trujillo, I., and Rallo, L. (2005). "Elaiografía Hispanica," in Variedades de Olivo en España, eds L. Rallo, D. Barranco, J. M. Caballero, C. Del Rio, A. Martin, J. Tous, and I. Trujillo (Madrid: Mundi-Prensa), 45-231.

Camposeo, S., and Godini, A. (2010). Preliminary observations about the performance of 13 varieties according to the super high density oliveculture training system in Apulia (southern Italy). Adv. Hortic. Sci. 24, 16-20.

Connor, D. J., and Gómez-del-Campo, M. (2013). Simulation of oil productivity and quality of $\mathrm{N}-\mathrm{S}$ oriented olive hedgerow orchards in response to structure and interception of radiation. Sci. Hortic. 150, 92-99. doi: 10.1016/j.scienta.2012.09.032

Connor, D. J., Gómez-del-Campo, M., and Comas, J. (2012). Yield characteristics of N-S oriented olive hedgerow orchards, cv. Arbequina. Sci. Hortic. (Amsterdam). 133, 31-36. doi: 10.1016/j.scienta.2011.10.008

Connor, D. J., Gómez-del-Campo, M., Rousseaux, M. C., and Searles, P. S. (2014). Structure, management and productivity of hedgerow olive orchards: a review. Sci. Hortic. 169, 71-93. doi: 10.1016/j.scienta.2014.02.010

Day, K., DeJong, T., and Johnson, R. (2005). Orchard-system configurations increase efficiency, improve profits in peaches and nectarines. Calif. Agric. 59, 75-79. doi: 10.3733/ca.v059n02p75

DeJong, T. M., and Doyle, J. F. (1985). The effect of row orientation on light distribution in hedgerow peach tree canopies. Acta Hortic. 173, 159-166. doi: 10.17660/ActaHortic.1985.173.18

De la Rosa, R., León, L., Guerrero, N., Rallo, L., and Barranco, D. (2007). Preliminary results of an olive cultivar trial at high density. Aust. J. Agric. Res. 58, 392-395. doi: 10.1071/AR06265

del Rio, C., and Romero, A. M. (1999). Whole, unmilled olives can be used to determine their oil content by nuclear magnetic resonance. Horttechnology 9 , 675-680.

Demšar, J. (2006). Statistical comparisons of classifiers over multiple data sets. J. Mach. Learn. Res. 7, 1-30.

Farina, V., Lo Bianco, R., and Inglese, P. (2005). Vertical distribution of crop load and fruit quality within vase- and Y-shaped canopies of 'Elegant Lady' peach. HortScience 40, 587-591.

Farinelli, D., and Tombesi, S. (2015). Performance and oil quality of "Arbequina" and four Italian olive cultivars under super high density hedgerow planting system cultivated in central Italy. Sci. Hortic. 192, 97-107. doi: 10.1016/j.scienta.2015.04.035

Fontanazza, G., Bartolozzi, F., and Vergari, G. (1998). Fs-17. Rev. Fruttic. 5, 61.

Freixa, E., Gil, J. M., Tous, J., and Hermoso, J. F. (2011). Comparative study of the economic viability of high- and super-high- density olive orchards in Spain. Acta Hortic. 924, 247-254. doi: 10.17660/ActaHortic.2011.924.31

Godini, A., Vivaldi, G., and Camposeo, S. (2011). Olive cultivars field-tested in super-high-density system in southern Italy. Calif. Agric. 65, 39-40. doi: 10.3733/ca.v065n01p39

Gómez-del-Campo, M., and García, J. M. (2012). Canopy fruit location can affect olive oil quality in "Arbequina" hedgerow orchards. J. Am. Oil Chem. Soc. 89, 123-133. doi: 10.1007/s11746-011-1900-2

Hampson, C. R., Quamme, H. A., Kappel, F., and Brownlee, R. T. (2004). Varying density with constant rectangularity: II. Effects on apple tree yield, fruit

\section{SUPPLEMENTARY MATERIAL}

The Supplementary Material for this article can be found online at: http://journal.frontiersin.org/article/10.3389/fpls.2016. 01226

size, and fruit color development in three training systems over ten years. HortScience 39, 507-511.

Heinicke, D. R. (1975). High Density Apple Orchards - Planning, Training and Pruning. Washington, DC: Handbook 4. U.S. Department of Agriculture.

Hermoso, J., Plana, J., Romero, A., and Tous, J. (2004). Performance of six olive oil cultivars in the South of Catalonia (Spain). Acta Hort. 791:333. doi: 10.17660/ActaHortic.2008.791.47

Larbi, A., Ayadi, M., Ben Dhiab, A., Msallem, M., and Caballero, J. M. (2011). Olive cultivars suitability for high-density orchards. Spanish J. Agric. Res. 9, 1279. doi: 10.5424/sjar/20110904-062-11

Larbi, A., Ayadi, M., Ben Dhiab, A., Msallem, M., and Caballero, J. M. (2012). Planting density affects vigour and production of "Arbequina" olive. Spanish J. Agric. Res. 10, 1081. doi: 10.5424/sjar/2012104-556-11

Lavee, S. (2006). Biennial bearing in olive. Olea 25, 5-13.

León, L., De La Rosa, R., Rallo, L., Guerrero, N., Barranco, D., Leon, L., et al. (2007). Influence of spacing on the initial production of hedgerow "Arbequina" olive orchards. Spanish J. Agric. Res. 5, 554-556. doi: 10.5424/sjar/20070 54-5358

López-Gutierrez, J., Ruiz-Hernández, J. M., and García de la Noceda, C. (2012). "Caracterización adicional de las masas de agua subterránea en riesgo de no cumplir los objetivos medio ambientales en 2015” in Las Aguas Subterráneas en la Planificación Hidrogeológica, ed L. Fernández Ruiz (Madrid: Instituto Geológico y Minero de España), 3-36.

Monselise, S. P., and Goldschmidt, E. E. (1982). Alternate bearing in fruit trees. Hortic. Rev. (Am. Soc. Hortic. Sci). 4, 128-173. doi: 10.1007/978-1-34906519-6_5

Moral, J., De la Rosa, R., Leon, L., Barranco, D., Michailides, T. J., and Trapero, A. (2008). High susceptibility of olive cultivar FS-17 to Alternaria alternata in Southern Spain. Plant Dis. 92, 1252. doi: 10.1094/PDIS-92-8$1252 \mathrm{~A}$

Moral, J., Jurado-Bello, J., Sánchez, M. I., de Oliveira, R., and Trapero, A. (2012). Effect of temperature, wetness duration, and planting density on olive anthracnose caused by Colletotrichum spp. Phytopathology 102, 974-981. doi: 10.1094/PHYTO-12-11-0343

Moral, J., Muñoz-Díez, C., González, N., Trapero, A., and Michailides, T. J. (2010). Characterization and pathogenicity of Botryosphaeriaceae species collected from olive and other hosts in Spain and California. Phytopathology 100, 1340-1351. doi: 10.1094/PHYTO-12-09-0343

Musacchi, S., Gagliardi, F., and Serra, S. (2015). New training systems for highdensity planting of sweet cherry. HortScience 50, 59-67.

Pastor, M., García-Vila, M., Soriano, M. A., Vega, V., and Fereres, E. (2007). Productivity of olive orchards in response to tree density. J. Hortic. Sci. Biotechnol. 82, 555-562. doi: 10.1080/14620316.2007. 11512273

Pearce, S. C., and Doberšek-Urbanc, S., (1967). The measurement of irregularity in growth and cropping. J. Hortic. Sci. 42, 295-305.

Proietti, P., Nasini, L., Reale, L., Caruso, T., and Ferranti, F. (2014). Productive and vegetative behavior of olive cultivars in super high-density olive grove. Sci. Agric. 72, 20-27. doi: 10.1590/0103-9016-2014-0037

Rallo, L., Barranco, D., Castro-Gacía, S., Connor, D. J., Gómez del Campo, M., and Rallo, P. (2013). High-density olive plantations. Hortic. Rev. (Am. Soc. Hortic. Sci). 41, 303-382. doi: 10.1002/9781118707418.ch07

Rallo, L., Torreno, P., Vargas, A., Alvarado, J., Lavee, S., and Klein, I. (1993). Dormancy and alternate bearing in olive. Acta Hortic. 356, 127-136.

Rius, X., and Lacarte, J. (2015). La Revolución del Olivar. El Cultivo en Seto. Barcelona: Agromillora.

Robinson, T. (2011). Advances in apple culture worldwide. Rev. Bras. Frutic. 33, 37-47. doi: 10.1590/S0100-29452011000500006 
Robinson, T., Hoying, S., Sazo, M.., DeMarree, A., and Dominguez, L. (2013). A vision for apple orchard systems of the future. N.Y. Fruit Q. 21, 11-16.

Robinson, T. L. (2005). Developments in high density sweet cherry pruning and training systems around the world. Acta Hortic. 667, 269-272. doi: 10.17660/ActaHortic.2005.667.39

Rosati, A., Paoletti, A., Caporali, S., and Perri, E. (2013). The role of tree architecture in super high density olive orchards. Sci. Hortic. 161, 24-29. doi: 10.1016/j.scienta.2013.06.044

Rosecrance, R. C., Krueger, W. H., Milliron, L., Bloese, J., Garcia, C., and Mori, B. (2015). Moderate regulated deficit irrigation can increase olive oil yields and decrease tree growth in super high density "Arbequina" olive orchards. Sci. Hortic. 190, 75-82. doi: 10.1016/j.scienta.2015.03.045

Ryugo, K., and Mikuckis, F. (1969). Sweet cherry. Hedgerow Planting. Calif. Agric. $23,14-15$.

Smart, R. E., Dick, J. K., Gravett, I. M., and Fisher, B. M. (1990). Canopy management to improve grape yield and wine quality-principles and practices. S. Afr. J. Enol. Vitucult. 11, 3-17.

Soil Survey Staff (2015). Illustrated Guide to Soil Taxonomy, Version 2. Lincoln: National Soil Survey Center.

Testi, L., Villalobos, F. J., and Orgaz, F. (2004). Evapotranspiration of a young irrigated olive orchard in southern Spain. Agric. For. Meteorol. 121, 1-18. doi: 10.1016/j.agrformet.2003.08.005

Tous, J., Romero, A., Hermoso, J., and Ninot, A. (2011). Mediterranean clonal selections evaluated for modern hedgerow olive oil production in Spain. Calif. Agric. 65, 34-40. doi: 10.3733/ca.v065n01p34

Tous, J., Romero, A., and Plana, J. (1998). IRTA-18 clon de la variedad de olivo “Arbequina." Agricultura 788, 224-225.

Tous, J., Romero, A., Plana, J., and Hermoso, J. F. (2008). Olive oil cultivars suitable for very-high density planting conditions. Acta Horti. 791, 403-408. doi: 10.17660/ActaHortic.2008.791.59

Tragsa (2015). Andalusian Phytosanitary Information Alert Network- RAIF. Available online at: http://www.tragsa.es/_layouts/GrupoTragsa/FichaProyecto.aspx?param=ENG.0000000187 (Accessed July 8, 2016).

Trentacoste, E. R., Connor, D. J., and Gómez-del-Campo, M. (2015a). Effect of row spacing on vegetative structure, fruit characteristics and oil productivity of N-S and E-W oriented olive hedgerows. Sci. Hortic. 193, 240-248. doi: 10.1016/j.scienta.2015.07.013

Trentacoste, E. R., Connor, D. J., and Gómez-del-Campo, M. (2015b). Row orientation: applications to productivity and design of hedgerows in horticultural and olive orchards. Sci. Hortic. 187, 15-29. doi: 10.1016/j.scienta.2015.02.032

Wagenmakers, P. S., and Callesen, O. (1995). Light distribution in apple orchard systems in relation to production and fruit quality. J. Hortic. Sci. 70, 935-948. doi: 10.1080/14620316.1995.11515369

Webster, A. D. (1993). New dwarfing rootstocks for apple, pear, plum and sweet cherry - a brief review. Acta Hortic. 349, 145-154. doi: 10.17660/ActaHortic.1993.349.21

Wheaton, T. A., Whitney, J. D., Castle, W. S., Muraro, R. P., Browning, H. W., and Tucker, D. P. H. (1995). Citrus scion and rootstock, topping height, and tree spacing affect tree size, yield, fruit quality, and economic return. J. Amer. Soc. Hort. Sci. 120, 861-870.

Widmer, A., and Krebs, C. (2001). Influence of planting density and tree form on yield and fruit quality of "Golden Delicious" and "Royal Gala" apples. Acta Hortic. 557, 235-241. doi: 10.17660/ActaHortic.2001.557.30

Conflict of Interest Statement: The authors declare that the research was conducted in the absence of any commercial or financial relationships that could be construed as a potential conflict of interest.

The reviewer TDJ declared a shared affiliation, though no other collaboration, with one of the authors JM to the handling Editor, who ensured that the process nevertheless met the standards of a fair and objective review.

Copyright (c) 2016 Díez, Moral, Cabello, Morello, Rallo and Barranco. This is an open-access article distributed under the terms of the Creative Commons Attribution License (CC BY). The use, distribution or reproduction in other forums is permitted, provided the original author(s) or licensor are credited and that the original publication in this journal is cited, in accordance with accepted academic practice. No use, distribution or reproduction is permitted which does not comply with these terms. 